\title{
UJI KINERJA DAN ANALISIS ENERGI MESIN PENEPUNG VERTIKAL (MILL DRYER VERTICAL) TIPE MDV-10 (Studi Kasus Techno Park Pangan Grobogan, Kabupaten Grobogan, Jawa Tengah)
}

\author{
FACHRY RIEZQIAPUTRA ERNAWAN*, M. ADE MOETANGAD \\ KRAMADIBRATA, ASRI WIDYASANTI
}

Departemen Teknik Pertanian dan Biosistem, Fakultas Teknologi Industri Pertanian, Universitas Padjadjaran

*Email: asri.widyasanti@unpad.ac.id

\begin{abstract}
ABSTRAK
Mesin penepung vertikal (mill dryer vertical) Tipe MDV-10 belum memiliki spesifikasi teknis, karena itu uji kinerja dan analisis energi ini perlu dilakukan agar mesin siap dipasarkan kepada masyarakat pengguna. Penelitian ini bertujuan untuk memperoleh data uji kinerja mesin mill dryer vertical dan data analisis penggunaan energi yang terjadi selama proses penepungan. Bahan yang digunakan dalam melakukan penelitian ini adalah singkong segar. Metode penelitian yang digunakan dalam penelitian ini adalah metode penelitian deskriptif. Hasil penelitian menunjukkan bahwa mesin mill dryer vertical memiliki nilai kapasitas aktual dan teoritis sebesar $21,15 \mathrm{~kg} / \mathrm{jam}$ dan $100 \mathrm{~kg} / \mathrm{jam}$, efesiensi mesin sebesar $21,155 \%$, persentase tepung tercecer sebesar $0 \%$, persentase susut massa sebesar 78,820\%, rendemen sebesar $21,18 \%$, kebutuhan daya sebesar $6,97 \mathrm{~kW}$, konsumsi bahan bakar sebesar 6,42 kg/jam, dan tingkat kebisingan mesin sebesar 96,68 dB. Adapun hasil tepung singkong memiliki nilai kadar air sebesar 9,68\%. Nilai indeks keseragaman tepung yang dihasilkan sebesar $1: 7,71: 108,46$ dengan modulus kehalusan sebesar 0,56 dan diamater tepung sebesar 0,006 inci. Sedangkan hasil analisis energi menunjukkan bahwa penggunaan energi dalam proses penepungan sebesar $83,881 \mathrm{MJ} / \mathrm{kg}$ tepung. Penggunaan total energi manusia sebesar $0,171 \mathrm{MJ} / \mathrm{kg}$. Penggunaan total energi langsung sebesar $2,332 \mathrm{MJ} / \mathrm{kg}$. Penggunaan total energi tak langsung sebesar $80,79 \mathrm{MJ} / \mathrm{kg}$.
\end{abstract}

Kata kunci: analisis energi, mill dryer vertical, tepung, uji kinerja

\begin{abstract}
Mill Dryer Vertical type MDV-10 does not have technical specifications, therefore this performance and energy analysis test need to be done, so the machine will ready to be marketed to the user community. The purpose of this research was to obtain data of the performance of mill dryer vertical machines and energy use analysis data that occurred during the milling process. The material used in conducting this research was fresh cassava. The research method used in this research was descriptive research method. The results showed that the vertical dryer mill machine had actual and theoretical capacity values of $21.15 \mathrm{~kg} / \mathrm{h}$ and $100 \mathrm{~kg} / \mathrm{h}$, machine efficiency of $21.155 \%$, percentage of flour scattered by $0 \%$, mass shrinkage percentage of $78.82 \%$, yield of $21.18 \%$, the power requirement was $6.97 \mathrm{~kW}$, the fuel consumption was $6.42 \mathrm{~kg} / \mathrm{hour}$, and the engine noise level was $96.68 \mathrm{~dB}$. The results of cassava flour have a water content of $9.68 \%$. Uniformity index value of flour produced was $1: 7.71: 108.46$ with fineness modulus of 0.56 and flour diamater of 0.006 inches. While the results of energy analysis show that the use of energy in the process of making flours was $83,881 \mathrm{MJ} / \mathrm{kg}$. The total use of human energy was $0.171 \mathrm{MJ} / \mathrm{kg}$. The total direct energy usage was $2.332 \mathrm{MJ} / \mathrm{kg}$. The total use of indirect energy was $80.79 \mathrm{MJ} / \mathrm{kg}$.
\end{abstract}

Keywords: energy analysis, flour, mill dryer vertical, performance test 


\section{PENDAHULUAN}

Metode penanaman padi secara Penepungan (milling) merupakan suatu proses penangganan pasca panen yang menggunakan prinsip pengecilan ukuran dimana bahan akan dihaluskan menjadi tepung atau bubuk. Pada era globalisasi perkembangan teknologi sangat begitu pesat, sehingga proses penepungan tidak lagi dilakukan secara manual melainkan menggunakan teknologi berupa mesin penepung dimana hal tersebut bertujuan untuk mendukung berjalannya dalam melakukan produksi tepung. Techno Park Pangan Grobogan merupakan salah satu instansi pengolahan bahan hasil pertanian yang beradaptasi dengan perkembangan teknologi yaitu dengan cara menggunakan mesin penepung vertikal mill dryer vertical) Tipe MDV-10 pada proses produksi tepung.

Mesin mill dryer vertical merupakan salah satu mesin untuk mengeringkan dan menepungkan berbagai macam bahan hasil pertanian. Mesin ini dirancangbangun berdasarkan kombinasi antara dua mesin yang sudah diproduksi sebelumnya yaitu mesin pulper coklat dan roaster. Mesin mill dryer vertical Tipe MDV-10 ini memiliki daya utama sebesar $10 \mathrm{HP}$ dengan daya separator sebesar 2 HP. Selain itu, mesin ini memiliki pisau pemotong Baja SKD 11 dan memakai bahan bakar LPG untuk unit pengeringnya serta bahan bakar listrik untuk unit penepungnya.

Prinsip kerja dari mesin mill dryer vertical yaitu mengecilkan ukuran bahan baku dengan cara menggiling bahan baku menggunakan hammer mill dan mengurangi kadar air bahan tersebut dengan cara mengalirkan udara panas dari unit pengering. Udara tersebut juga digunakan sebagai media pembawa ke bagian outlet. Salah satu manfaat penggunaan mesin mill dryer vertical yaitu proses produksi yang cepat dengan hasil tepung yang halus.

Namun, kurangnya informasi mengenai kinerja mesin serta besarnya penggunaan energi yang terjadi selama proses pembuatan tepung tersebut maka diperlukan pengujian kinerja mesin untuk mengetahui sejauh mana kinerja mesin beroperasi dengan baik dan analisis energi. Analisis energi dilakukan sebagai cara untuk menentukan penggunaan energi pada setiap proses pembuatan tepung. Hal ini dilakukan dengan cara mengaudit energi untuk memberikan gambaran konsumsi energi agar sumbersumber pemborosan energi dapat diketahui untuk meningkatkan efisiensi pada proses pembuatan tepung. 


\section{METODE PENELITIAN}

Penelitian ini dilaksanakan pada bulan Desember 2017 sampai dengan Januari 2018 bertempat di Techno Park Pangan Grobogan, Kabupaten Grobogan, Provinsi Jawa Tengah.

\section{Alat dan Bahan}

Alat yang digunakan yaitu timbangan digital, meteran, stopwatch, sound level mete, clamp meter, tachometer, laptop, mesin slicer, mesin pres dan pisau.

Bahan yang digunakan dalam penelitian ini adalah singkong manggu sebanyak $500 \mathrm{~kg}$. Data penelitian yang digunakan merupakan data primer dan data sekunder. Data primer bersumber dari penelitian langsung yang berasal dari pengamatan, hasil wawancara, dan perhitungan. Data sekunder berasal dari jadwal kegiatan, data dan spesifikasi mesin penepung vertikal, serta studi literatur.

\section{Tahapan Penelitian}

Tahapan penelitian yang dilakukan secara umum dibagi menjadi dua, yaitu uji kinerja dan analisis energi. Paramerter uji kinerja mesin meliputi kapasitas aktual dan teoritis penepungan, efesiensi penepungan, persentase tepung tercecer, persentase susut hasil, kebutuhan daya, rendemen penepungan, konsumsi bahan bakar, tingkat kebisingan, diameter ratarata partikel tepung, dan modulus kehalusan. Uji kinerja

Ada pun parameter analisis energi meliputi total energi biologis, total energi langsung dan total energi tidak langsung. Parameter tersebut dihitung pada setiap proses yang dilakukan selama melakukan produksi tepung singkong. Digram alir tahapan penelitian seperti yang disajikan pada Gambar 1.

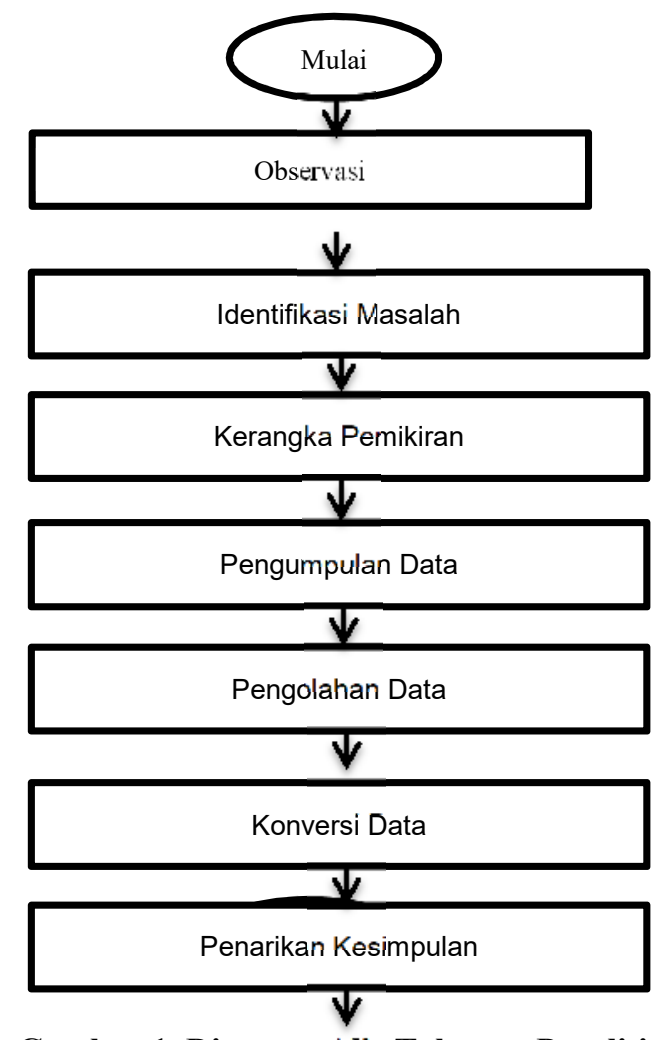

Gambar 1. Diagram Alir Tahapan Penelitian

HASIL DAN PEMBAHASAN

Kondisi Techno Park Pangan Grobogan

Penelitian ini dilakukan di Ruang Produksi Tepung Mokaf Techno Park 
Pangan Grobogan, dimana Techno Park ini berada di Desa Dapurno, Kecamatan Wirosari, Kabupaten Grobagan, Jawa Tengah. Techno Park Pangan Grobogan ini melakukan produksi tepung singkong 5 hari dalam seminggu.

Proses produksi tepung singkong yang dilakukan di Techno Park Pangan Grobogan dimulai dari proses persiapan bahan baku (singkong). Techno Park Pangan Grobogan dapat memproduksi tepung singkong yang siap produksi di setiap harinya, namun karena kurangnya pemasaran yang baik sehingga tepung yang sudah diproduksi hanya tersimpan di gudang saja sehingga Techno Park Pangan Grobogan tidak melakukan produksi rutin atau melakukan produksi tepung pada waktu tertentu saja.

\section{Proses Pengolahan Tepung di Techno Park Pangan Grobogan}

Proses pengolahan tepung di Techno Park Pangan Grobogan memiliki 6 kegiatan yaitu proses persiapan bahan baku, pengupasan kulit singkong, pemotongan singkong, pengepresan singkong, penepungan dan pengemasan. Pada keenam proses tersebut masingmasing memiliki masukan energi yang akan dianalisis penggunaan energinya.

\section{Uji Kinerja}

\section{Kapasitas Aktual Penepungan}

Kapasitas penepungan adalah kemampuan mesin dalam melakukan penepungan dengan jumlah tertentu dalam satu jam. Kapastitas tersebut terdiri atas kapasitas aktual dan kapasitas teoritis. Adapun nilai kapasitas aktual penepungan didapat dari hasil perbandingan massa tepung singkong yang dibagi dengan waktu proses penepungan. Adapun nilai kapasitas aktual mesin penepung vertikal (mill dryer vertical) tipe MDV-10 yang dihasilkan sebesar 21,15 kg/jam.

Tabel 1. Hasil Perhitungan Kapasitas Aktual Penepungan

\begin{tabular}{cccc}
\hline Ulangan & $\begin{array}{c}\text { Massa } \\
\text { Tepung } \\
\text { (kg) }\end{array}$ & $\begin{array}{c}\text { Waktu } \\
\text { Penepungan } \\
\text { (jam) }\end{array}$ & $\begin{array}{c}\text { Kapasitas } \\
\text { Aktual } \\
\text { (kg/jam) }\end{array}$ \\
\hline 1 & 20,60 & 0,94 & 21,87 \\
2 & 21,76 & 1,04 & 20,93 \\
3 & 21,76 & 1,05 & 20,86 \\
4 & 21,95 & 0,95 & 21,66 \\
5 & 20,96 & 1,02 & 20,47 \\
\hline Rata-rata & 21,18 & 1,00 & 20,15 \\
\hline
\end{tabular}

\section{Kapasitas Teoritis Penepungan}

Parameter kedua yaitu kapasitas teoritis penepungan. Kapasitas teoritis penepungan merupakan kapasitas mesin berdasarkan perhitungan variabel dan dimensi elemen mesin penepung. Nilai kapasitas mesin penepung vertikal (mill dryer vertical) Tipe MDV-10 sebesar 100 $\mathrm{kg} / \mathrm{jam}$. 


\section{Efesiensi Penepungan}

Efisiensi penepungan merupakan nilai persentase perbandingan antara kapasitas aktual penepungan dengan kapasitas teoritis penepungan. Suatu mesin penepung dikatakan baik dalam melakukan proses penepungan apabila mesin penepung tersebut dapatkan menghasilkan efesiensi mendekati 100\%. Pada Standar Uji Nasional, mesin penepung harus memiliki efisiensi penepungan mininal sebesar $90 \%$. Namun pada penelitian ini, efisiensi yang terjadi pada mesin penepung hanya sebesar 21,15\%. Hal tersebut menandakan bahwa efesiensi mesin penepung vertikal (mill dryer vertical) Tipe MDV-10 ini masih tergolong kecil.

\section{Persentase Kehilangan Massa Pada Proses Penepungan}

Persentase kehilangan massa yang terjadi pada proses penepungan meliputi persentase susut massa, persentase tepung tercecer dan rendemen penepungan.

Nilai persentase susut massa didapatkan berdasarkan perbandingan berat bahan masukan (irisan singkong) dikurangi berat tepung singkong yang dihasilkan dari saluran keluaran dibagi terhadap berat bahan masukan (irisan singkong) tersebut, sehingga didapat nilai persentase susut massa dari mesin penepung vertikal (mill dryer vertical) Tipe MDV-10 sebesar 78,82\%.

Tabel 2. Hasil Persentase Susut Massa

\begin{tabular}{cccc}
\hline Ulangan & $\begin{array}{c}\text { Massa } \\
\text { Awal } \\
\text { Bahan } \\
(\mathbf{k g})\end{array}$ & $\begin{array}{c}\text { Massa } \\
\text { Tepung } \\
\text { Singkong } \\
\mathbf{( k g )}\end{array}$ & $\begin{array}{c}\text { Persentase } \\
\text { Susut } \\
\text { Massa } \\
\mathbf{( \% )}\end{array}$ \\
\hline 1 & 100 & 20,60 & 79,40 \\
2 & 100 & 21,78 & 78,22 \\
3 & 100 & 21,95 & 78,05 \\
4 & 100 & 20,63 & 79,37 \\
5 & 100 & 20,96 & 79,04 \\
\hline Rata-rata & 100 & 21,18 & 78,82 \\
\hline
\end{tabular}

Parameter kedua yang diamati adalah persentase tepung yang tercecer pada proses penepungan. Persentase tepung yang tercecer merupakan irisan singkong yang tergiling yang keluar tidak melalui saluran keluaran, baik tepung yang tertinggal di pemukul, dinding, mulut outlet ataupun irisan singkong yang tidak tergiling dan tertinggal di ruang penepung. Nilai rata-rata persentase tepung singkong yang tercecer sebesar $0 \%$. Nilai tersebut didapatkan karena tidak adanya irisan singkong yang tidak tergiling ataupun tepung yang yang tercecer, sehingga mesin penepung vertikal (mill dryer vertical) Tipe MDV10 ini dapat dikatakan baik dalam melakukan proses penepungan. 
Tabel 3. Hasil Persentase Tepung Tercecer

\begin{tabular}{cccc}
\hline Ulangan & $\begin{array}{c}\text { Massa } \\
\text { Awal } \\
\text { Bahan } \\
(\mathbf{k g})\end{array}$ & $\begin{array}{c}\text { Massa } \\
\text { Bahan } \\
\text { Tercecer } \\
(\mathbf{k g})\end{array}$ & $\begin{array}{c}\text { Persentase } \\
\text { Tepung } \\
\text { Tercecer } \\
(\%)\end{array}$ \\
\hline 1 & 100 & 0 & 0 \\
2 & 100 & 0 & 0 \\
3 & 100 & 0 & 0 \\
4 & 100 & 0 & 0 \\
5 & 100 & 0 & 0 \\
\hline Rata-rata & 100 & 0 & 0 \\
\hline
\end{tabular}

Parameter terakhir yaitu rendemen penepungan. Rendemen penepungan adalah pengujian dengan cara mempersentasekan hasil irisan singkong yang telah menjadi tepung dengan keseluruhan irisan singkong yang dimasukkan ke dalam mesin penepung. Suatu mesin dikatakan baik apabila mesin tersebut memiliki rendemen yang nilainya mendekati 100\% atau bahan yang masuk ke dalam mesin tersebut terproses seluruhnya. Nilai rendemen penepungan rata-rata yang dihasilkan sebesar 21,18\%. Hasil tersebut mengindikasikan bahwa dari $100 \mathrm{~kg}$ irisan singkong yang masuk ke dalam mesin penepung, menghasilkan $21,18 \mathrm{~kg}$ tepung singkong dimana sisanya merupakan udara kotor yang tertampung di dust collector, serat atau ampas bahan yang keluar dari output serta kadar air singkong itu sendiri. Jika dilihat dari hasil rendemen yang didapatkan, rendemen yang dihasilkan sangatlah kecil karena berdasarkan SNI 0838-4:2014 syarat mutu unjuk kerja mesin penepung ubi kayu tipe hammer mill, efisiensi penepungan minimum yang diizinkan sebesar $90 \%$.

Tabel 4. Hasil Persentase Rendemen Penepungan

\begin{tabular}{cccc}
\hline Ulangan & $\begin{array}{c}\text { Massa } \\
\text { Awal } \\
\text { Bahan } \\
\mathbf{( k g )}\end{array}$ & $\begin{array}{c}\text { Massa } \\
\text { Tepung } \\
\text { Singkong } \\
\mathbf{( k g )}\end{array}$ & $\begin{array}{c}\text { Rendemen } \\
\text { Tepung } \\
\mathbf{( \% )}\end{array}$ \\
\hline 1 & 100 & 20,60 & 20,60 \\
2 & 100 & 21,78 & 21,78 \\
3 & 100 & 21,95 & 21,95 \\
4 & 100 & 20,63 & 20,63 \\
5 & 100 & 20,96 & 20,96 \\
\hline Rata-rata & 100 & 21,18 & 21,18 \\
\hline
\end{tabular}

\section{Kebutuhan Daya}

Kebutuhan daya diukur bertujuan untuk mengetahui banyak energi listrik yang terjadi saat proses penepungan pada mesin penepung vertikal (mill dryer vertical) Tipe MDV-10 serta untuk mengetahui apakah daya yang dibutuhkan oleh mesin sudah sesuai atau tidak dengan daya yang tersedia pada motor penggerak. Pada mesin penepung vertikal (mill dryer vertical) Tipe MDV-10 ini memiliki 9 motor penggerak yang terdiri atas blower, separatator, pulse jet, screw conveyor, MDV (penggiling), pompa pendingin, burner, kompresor dan output.

Tabel 5. Hasil Pengukuran Kebutuhan Daya

\begin{tabular}{lccc}
\hline \multirow{1}{*}{ Motor } & \multicolumn{3}{c}{ Parameter } \\
\cline { 2 - 4 } & $\begin{array}{c}\text { Tegangan } \\
\text { Listrik } \\
(\mathbf{V})\end{array}$ & $\begin{array}{c}\text { Arus } \\
\text { Listrik } \\
(\mathbf{A})\end{array}$ & $\begin{array}{c}\text { Daya } \\
\text { Motor } \\
(\mathbf{k W})\end{array}$ \\
\hline Blower & 380 & 4,72 & 1,79 \\
Separator & 380 & 3,36 & 1,28 \\
Pulse Jet & 380 & 0,15 & 0,06 \\
Screw Conveyor & 380 & 0,31 & 0,12 \\
MDV & 380 & 7,18 & 2,73 \\
Pompa Pendingin & 380 & 0,83 & 0,32 \\
Burner & 380 & 1,46 & 0,55 \\
Kompresor & 380 & 0,13 & 0,05 \\
Output & 380 & 0,20 & 0,08 \\
\hline Total & \multicolumn{4}{|}{6,97} \\
\hline
\end{tabular}


Berdasarkan hasil pengukuran kebutuhan daya rata-rata dari Tabel 5, maka mesin penepung membutuhkan daya sekitar 6,97 kW. Daya tersebut merupakan daya total dari semua motor yang terdapat pada mesin penepung vertikal (mill dryer vertical) Tipe MDV-10 yang bekerja ketika proses penepungan berlangsung. Daya motor total yang terdapat pada spesifikasi mesin adalah $10 \mathrm{HP}$ atau sekitar 7,457 kW. Dari hasil tersebut dapat disimpulkan bahwa daya untuk proses penepungan dapat dipenuhi oleh daya yang tersedia pada motor penggerak.

\section{Konsumsi Bahan Bakar}

Konsumsi bahan bakar LPG diukur bertujuan untuk mengetahui banyaknya bahan bakar yang terpakai selama proses penepungan pada mesin penepung vertikal (mill dryer vertical) Tipe MDV-10. Bahan bakar yang digunakan pada mesin penepung vertikal (mill dryer vertical) Tipe MDV-10 adalah dua buah tabung gas lpg dengan berat bersih masing-masing sebesar $27,1 \mathrm{~kg}$ dimana gas tersebut digunakan untuk melakukan proses pengeringan di dalam mesin penepung
Tabel 6. Hasil Konsumsi Bahan Bakar

\begin{tabular}{cccc}
\hline Ulangan & $\begin{array}{c}\text { Berat } \\
\text { LPG } \\
\mathbf{( k g )}\end{array}$ & $\begin{array}{c}\text { Waktu } \\
\text { Penepungan } \\
\text { (jam) }\end{array}$ & $\begin{array}{c}\text { Konsumsi } \\
\text { Bahan } \\
\text { Bakar } \\
(\mathbf{k g} / \mathbf{j a m})\end{array}$ \\
\hline 1 & 6,31 & 0,94 & 6,70 \\
2 & 6,48 & 1,04 & 6,23 \\
3 & 6,53 & 1,05 & 6,21 \\
4 & 6,37 & 0,95 & 6,68 \\
5 & 6,43 & 1,02 & 6,28 \\
\hline Rata-rata & 6,42 & 1,00 & 6,42 \\
\hline
\end{tabular}

Berdasarkan data pengujian pada Tabel di atas, dapat diketahui bahwa dari 5 kali percobaan dalam melakukan penepungan, konsumsi bahan bakar yang didapat sebesar $6,42 \mathrm{~kg} / \mathrm{jam}$ dengan waktu rata-rata penepungan sebesar 1 jam. Adapun penurunan massa dua buah tabung bahan bakar LPG dari 5 percobaan penepungan tersebut sebesar $32,18 \mathrm{~kg}$.

\section{Tingkat Kebisingan}

Tingkat kebisingan mesin diukur bertujuan untuk mengetahui seberapa besar tingkat kebisingan yang dihasilkan ketika mesin sedang beroperasi. Mesin yang memiliki tingkat kebisingan yang rendah dapat memberikan kenyamanan dan keamanan terhadap operator mesin. Sebaliknya, apabila mesin memiliki tingkat kebisingan yang tinggi dapat mengganggu dan membahayakan operator karena tidak nyaman dan tidak aman. 
Tabel 7. Hasil Tingkat Kebisingan

\begin{tabular}{ccc}
\hline Ulangan & Waktu & Kebisingan (dB) \\
\hline 1 & 10 menit ke -1 & 95,50 \\
2 & 10 menit ke -2 & 97,00 \\
3 & 10 menit ke -3 & 97,00 \\
4 & 10 menit ke -4 & 97,10 \\
5 & 10 menit ke -5 & 96,80 \\
\hline \multicolumn{2}{c}{ Rata-rata } & 96,68 \\
\hline
\end{tabular}

Berdasarkan data pengujian pada Tabel 7, dapat diketahui bahwa dari 5 kali pengukuran dalam melakukan penepungan, tingkat kebisingan yang terjadi sebesar 96,68 dB. Menurut SNI 0838-4:2014, tingkat kebisingan yang diizinkan untuk mesin penepung sebesar $90 \mathrm{~dB}$. Hal tersebut menunjukkan bahwa tingkat kebisingan yang terjadi tinggi. Salah satu faktor yang mempengaruhi tingginya tingkat kebisingan mesin penepung vertikal (mill dryer vertical) Tipe MDV-10 ini adalah suara dari 9 motor listrik yang beroperasi secara bersamaan ketika mesin beroperasi.

\section{Mutu Hasil Penepungan}

\section{Kadar Air Tepung}

Pengujian kadar air tepung singkong menggunakan kadar air basis basah yang disesuaikan dengan SNI 01-2997-1996 tentang tepung singkong. Hasil perhitungan rata-rata dari kadar air basis basah tepung singkong yang didapat sebesar 9,68\%. Nilai ini menunjukkan bahwa tepung yang dihasilkan oleh mesin MDV-10 sangat kering yang mengakibatkan ketika dicampur dengan bahan, tepung akan mudah larut dalam air. Namun, nilai tersebut telah memenuhi standar uji yang terdapat pada SNI 012997-1996 dimana nilai maksimum untuk kadar air basah yang diijinkan tidak boleh melebihi $12 \%$. Hal tersebut menunjukkan bahwa proses pengeringan yang terjadi pada mesin penepung vertikal (mill dryer vertical) Tipe MDV-10 sudah tergolong baik.

\section{Indeks Keseragaman, Modulus} Kehalusan dan Diameter Rata-rata

\section{Partikel Tepung}

Indeks keseragaman merupakan perbandingan yang menyatakan fraksifraksi kasar, sedang dan halus dari tepung yang dihasilkan, sehingga akan diketahui tingkat keseragaman tepung tersebut. Penentuan nilainya berdasarkan pada perbandingan antara fraksi kasar, sedang dan halus menggunakan ayakan tepung tersebut. Penentuan nilainya berdasarkan pada perbandingan antara fraksi kasar, sedang dan halus menggunakan ayakan Tyler (Tyler sieves). Ayakan Tyler tersebut digunakan untuk mengelompokkan setiap fraksi, dengan lama pengayakan selama 15 menit dan massa sampel tepung yang diayak 
sebanyak 250 g (Henderson dan Perry, 1976).

Pembagian fraksi tepung pada penelitian ini menggunakan ayakan Tyler dan dibantu dengan menggunakan mesin pengayak. Hasil pengayakan lalu digolongkan ke dalam fraksi kasar, sedang dan halus.

Berdasarkan data hasil perhitungan, hasil perbandingan antara fraksi kasar, sedang dan halus yang didapat adalah 1 : 7,71:108,46, sedangkan standar kehalusan tepung yang baik dan layak untuk digunakan menurut Henderson dan Perry (1976) adalah 1:6:3. Perbedaan tersebut dapat dilihat pada hasil perbandingan antara fraksi sedang dan halus. Hal tersebut dikarenakan dari 250 gram sampel tepung singkong yang diayak, persentase tepung yang lolos ayakan pada fraksi halus (mesh 140 dan pan) memiliki nilai yang sangat besar besar jika dibandingkan dengan fraksi kasar maupun fraksi sedang.

Faktor lain yang mempengaruhi tepung yang adalah kecepetan putar gilingan yang sangat cepat yaitu sebesar 4000 rpm dimana kecepatan putar tersebut tidak sebanding dengan banyaknya bahan yang dibawa oleh screw conveyor dari hopper. Dari hasil tersebut dapat disimpulkan bahwa tepung pada penelitian ini mempunyai tingkat kehalusan yang sangat tinggi, namun jika dibandingkan dengan standar kehalusan yang diinginkan, tepung tersebut tidaklah sesuai karena tepung mempunyai kemungkinan yang mudah larut jika akan diolah menjadi produk olahan pangan.

Ada pun hasil perhitungan untuk parameter modulus kehalusan tepung yaitu sebesar 0,56 dan diameter rata-rata partikel tepung singkong sebesar 0,006 inci. Nilai diameter tersebut termasuk ke dalam kriteria ukuran saringan 100 mesh yaitu sebesar 0,0058 inci. Hal tersebut terbukti dari hasil pengukuran yang telah diukur dimana banyaknya persentase tepung yang tidak lolos pada mesh 100 dibandingkan dengan mesh lainnya

\section{Analisis Energi}

\section{Rendemen Proses Pembuatan Tepung} Singkong

Rendemen yang dihitung merupakan sampel dari rata-rata 5 kali ulangan (5 hari proses) yaitu perbandingan massa tepung singkong dengan massa singkong segar. Rata-rata massa singkong segar sebelum proses pengolahan adalah $110,19 \mathrm{~kg}$, sedangkan massa rata-rata tepung singkong sebanyak 21,182 $\mathrm{kg}$ sehingga rendemen pada proses 
pembuatan tepung singkong sebesar $19,22 \%$.

Rendemen tiap proses dihitung melalui perbandingan massa tepung singkong setelah proses (output) dengan massa singkong sebelum proses (input). Proses yang memiliki rendemen paling banyak dari proses lainnya yaitu proses penpungan dengan rendemen sebesar 21,182\%. Hal tersebut terjadi karena terdapat pengurangan kadar air yang signifikan pada proses penepungan.

Pengurangan kadar air pada proses penepungan terjadi karena adanya proses pengecilan ukuran dari bahan baku berupa irisan singkong yang diolah dengan penggiling yang terdapat di dalam mesin, sehingga menghasilkan butiran-butiran (powder) tepung. Selain pengecilan ukuran, terdapat proses pengeringan di dalam mesin tersebut. Pengeringan terjadi dengan mengalirkan udara panas sebagai media untuk meneruskan tepung yang sudah tergiling ke proses pengeluaran (output). Pengeringan juga bertujuan untuk mengurangi kadar air bahan sehingga rendemen pada proses penepungan yang dihasilkan besar dibanding proses lainnya.

\section{Penggunaan Energi Pada Proses Pembuatan Tepung Singkong}

Perhitungan penggunaan energi pada proses poembuatan tepung singkong di Techno Park Pangan Grobogan dimulai dari kegiatan persiapan bahan baku. Kegiatan atau proses yang dilakukan meliputi proses persiapan bahan baku, pengupasan kulit singkong, pemotongan singkong, pengepresan singkong, penepungan, dan pengemsan.

\section{Penggunaan Energi Pada Proses Persiapan Bahan Baku}

Penggunaan energi pada proses persiapan bahan baku meliputi energi manusia, dan energi tak langsung ember. Energi manusia digunakan untuk proses pengangkutan bahan-bahan menggunakan ember. Energi tak langsung terdapat pada ember.

Tabel 8. Penggunaan Energi Proses Persiapan Bahan Baku

\begin{tabular}{clc}
\hline \multirow{2}{*}{ No } & \multicolumn{1}{c}{ Jenis Energi } & $\begin{array}{c}\text { Nilai Energi } \\
(\mathbf{M J} / \mathbf{k g})\end{array}$ \\
\hline 1 & Energi Manusia & 0,042 \\
2 & Energi Tidak Langsung & 1,07 \\
\hline \multicolumn{2}{c}{ Total } & 1,112 \\
\hline
\end{tabular}

Energi tak langsung mempunyai presentasi dari total penggunaan energi proses persiapan bahan baku sebesar $96,22 \%$. Energi manusia yang terlibat pada proses persiapan bahan baku sebesar 0,042 $\mathrm{MJ} / \mathrm{kg}$ dengan presentase 3,78\%. 


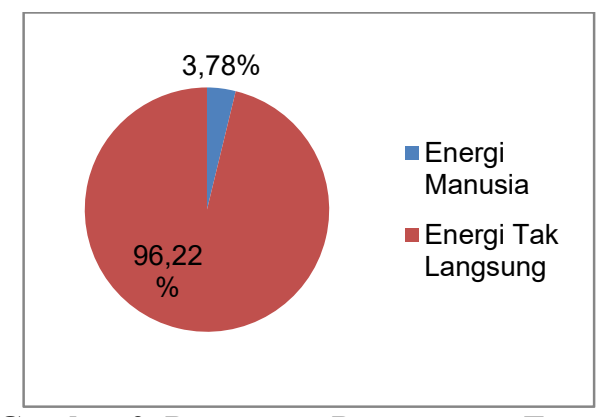

Gambar 2. Persentase Penggunaan Energi pada Proses Persiapan Bahan Baku

\section{Penggunaan Energi Pada Proses Pemotongan Kulit Singkong}

Penggunaan energi pada proses pengupasan kulit singkong meliputi energi manusia, dan energi tak langsung. Energi manusia digunakan untuk mengupas kulit singkong. Energi tak langsung terdapat pada ember dan pisau.

Tabel 9. Penggunaan Energi Proses Pengupasan Kulit Singkong

\begin{tabular}{clc}
\hline \multirow{2}{*}{ No } & \multicolumn{1}{c}{ Jenis Energi } & $\begin{array}{c}\text { Nilai Energi } \\
(\mathbf{M J} / \mathbf{k g})\end{array}$ \\
\hline 1 & Energi Manusia & 0,589 \\
2 & Energi Tidak Langsung & 1,31 \\
\hline & Total & 1,899 \\
\hline
\end{tabular}

Energi tak langsung dari total penggunaan energi proses pengupasan kulit singkong sebesar 1,31 MJ/kg dengan persentase sebesar 68,98\%. Adapun persentase energi manusia yang terlibat pada proses persiapan pengupasan kulit singkong sebesar $\mathrm{MJ} / \mathrm{kg}$ dengan persentase $31,02 \%$.

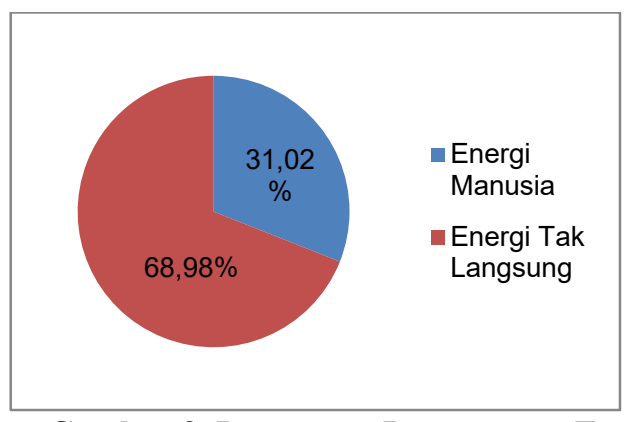

Gambar 3. Persentase Penggunaan Energi pada Proses Pengupasan Kulit Singkong

\section{Penggunaan Energi Pada Proses Pemotongan Singkong}

Penggunaan energi pada proses pemotongan singkong meliputi energi manusia, energi langsung dan energi tak langsung. Energi manusia digunakan sebagai operator mesin rajang dan memasukkan bahan ke dalam mesin tersebut. Energi langsung adalah energi listrik yang terjadi selama mengunakan mesin rajang. Energi tak langsung terdapat pada mesin rajang dan ember.

Tabel 10. Penggunaan Energi Proses Pemotongan Singkong

\begin{tabular}{clc}
\hline No & \multicolumn{1}{c}{ Jenis Energi } & $\begin{array}{c}\text { Nilai Energi } \\
\text { (MJ/kg) }\end{array}$ \\
\hline 1 & Energi Manusia & 0,057 \\
2 & Energi Langsung & 0,060 \\
3 & Energi Tidak Langsung & 4,55 \\
\hline & Total & 4,667 \\
\hline
\end{tabular}

Energi tak langsung dari total penggunaan energi proses pemotongan singkong sebesar 4,55 $\mathrm{MJ} / \mathrm{kg}$ dengan persentase sebesar 97,493\%. Energi manusia yang terlibat pada proses pemotongan singkong sebesar 0,057 $\mathrm{MJ} / \mathrm{kg}$ dengan persentase 1,221\%. 
Adapun energi penggunaan listrik sebesar $0,060 \mathrm{MJ} / \mathrm{kg}$ dengan persetanse $1,286 \%$.

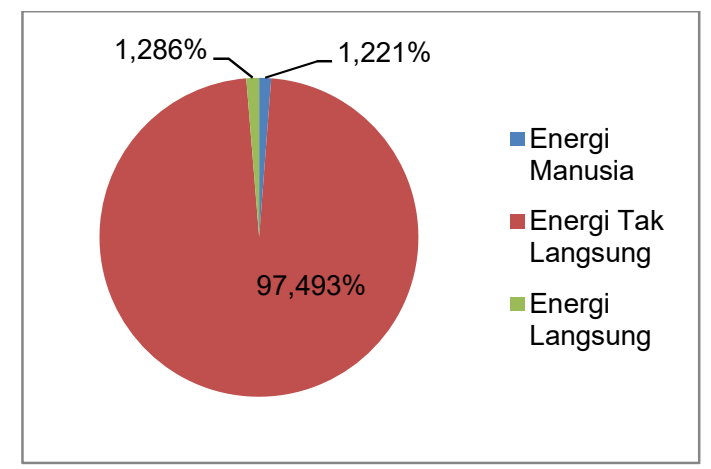

Gambar 4. Persentase Penggunaan Energi pada Proses Pemotongan Singkong

\section{Penggunaan Energi Pada Proses}

\section{Pengepresan Singkong}

Penggunaan energi pada proses pengepresan singkong meliputi energi manusia, energi langsung dan energi tak langsung. Energi manusia digunakan sebagai operator mesin pres dan memasukkan bahan ke dalam mesin tersebut. Energi langsung adalah energi listrik yang terjadi selama mengunakan mesin pres. Energi tak langsung terdapat pada mesin pres.

Tabel 11. Penggunaan Energi Proses Pengepresan Singkong

\begin{tabular}{clc}
\hline No & \multicolumn{1}{c}{ Jenis Energi } & $\begin{array}{c}\text { Nilai Energi } \\
\text { (MJ/kg) }\end{array}$ \\
\hline 1 & Energi Manusia & 0,044 \\
2 & Energi Langsung & 0,016 \\
3 & Energi Tidak Langsung & 22,64 \\
\hline \multicolumn{2}{c}{ Total } & 22,7 \\
\hline
\end{tabular}

Energi tak langsung dari total penggunaan energi proses pengepresan singkong sebesar 22,64 MJ/kg dengan persentase sebesar 99,736\%. Adapun persentase energi manusia yang terlibat pada proses pengepresan sebesar 0,044 $\mathrm{MJ} / \mathrm{kg}$ dengan persentase $0,193 \%$ dan energi langsung yang terlibat sebesar 0,016 dengan persentase sebesar $0,07 \%$.

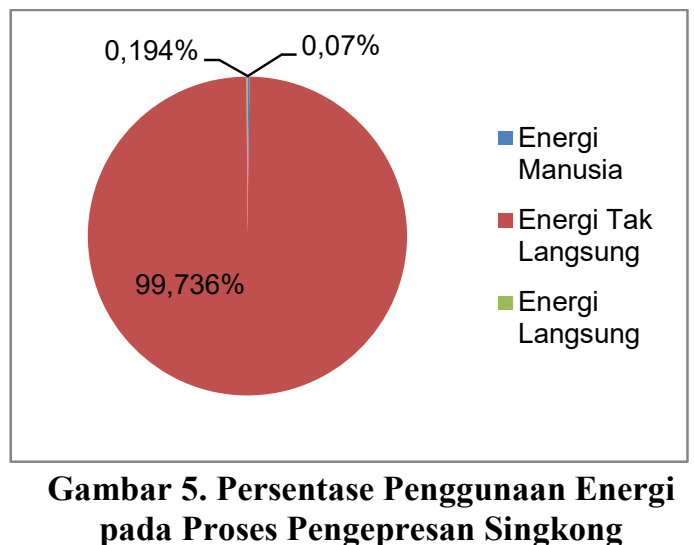

\section{Penggunaan Energi Pada Proses Penepungan Singkong}

Penggunaan energi pada proses penepungan meliputi energi manusia, energi langsung dan energi tak langsung. Energi manusia digunakan sebagai operator mesin penepung vertikal (mill dryer vertical) tipe MDV-10 dan memasukkan bahan ke dalam mesin tersebut. Energi langsung adalah energi listrik yang terjadi selama mengunakan mesin penepung vertikal (mill dryer vertical) tipe MDV-10. Energi tak langsung terdapat pada mesin penepung vertikal (mill dryer vertical) tipe MDV10. 
Tabel 12. Penggunaan Energi Proses Penepungan Singkong

\begin{tabular}{|c|c|c|}
\hline No & Jenis Energi & $\begin{array}{l}\text { Nilai Energi } \\
\text { (MJ/kg) }\end{array}$ \\
\hline 1 & Energi Manusia & 0,027 \\
\hline 2 & Energi Langsung & 2,256 \\
\hline 3 & Energi Tidak Langsung & 51,22 \\
\hline & Total & 53,503 \\
\hline
\end{tabular}

Energi tak langsung mempunyai persentase dari total penggunaan energi proses penepungan sebesar 95,733\%. Energi manusia yang terlibat pada proses penepunan sebesar $0,027 \mathrm{MJ} / \mathrm{kg}$ dengan persentase $0,050 \%$ dan energi langsung penepungan sebesar 2,256 MJ/kg dengan persentase sebesar $4,217 \%$.

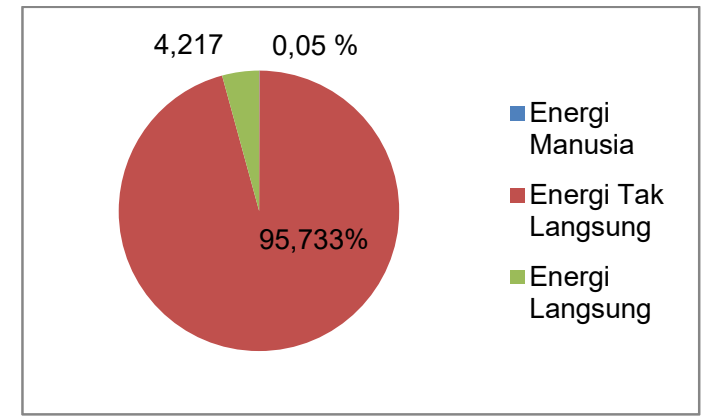

Gambar 6. Persentase Penggunaan Energi pada Proses Penepungan Singkong

\section{Masukan Energi Total Proses}

\section{Pembuatan Tepung Singkong}

Secara keseluruhan kegiatan pembuatan tepung singkong terdiri atas persiapan bahan baku, pengupasan kulit singkong, pemotongan singkong, pengepresan singkong, dan penepungan. Masukan energi total pada proses pembuatan tepung singkong yang dilakukan di Techno Park Pangan Grobogan sebesar 83,881 MJ/kg tepung singkong.
Tabel 13. Masukan Energi Proses Pembuatan Tepung Singkong

\begin{tabular}{crrrr}
\hline & \multicolumn{4}{c}{$\begin{array}{c}\text { Konsumsi Energi } \\
\text { (MJ/kg) }\end{array}$} \\
\cline { 2 - 5 } Proses & \multicolumn{4}{c}{ Tepung Singkong } \\
& EM & \multicolumn{1}{c}{ EL } & ETL & $\begin{array}{c}\text { Total } \\
\text { Energi }\end{array}$ \\
\hline 1 & 0,042 & 0 & 1,07 & 1,112 \\
2 & 0,589 & 0 & 1,31 & 1,899 \\
3 & 0,057 & 0,060 & 4,55 & 4,667 \\
4 & 0,044 & 0,016 & 22,64 & 22,7 \\
5 & 0,027 & 2,256 & 51,22 & 53,503 \\
\hline Total & 0,759 & 2,332 & 80,79 & 83,881 \\
\hline
\end{tabular}

Persentase penggunaan energi yang terbesar adalah proses penenpungan sebesar $63,784 \%$ dari penggunaan energi total untuk proses pembuatan tepung singkong, sedangkan persentase penggunaan energi ada proses persiapan bahan baku merupakan persentase masukan energi terkecil yaitu sebesar $1,326 \%$.

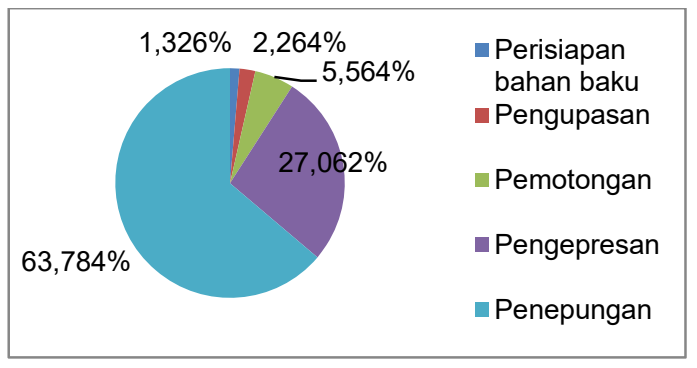

Gambar 7. Masukan Energi Total Proses Pembuatan Tepung Singkong

Besarnya energi yang terjadi untuk proses penepungan dikarenakan banyaknya masukan energi yang digunakan, salah satunya adalah energi listrik. Energi listirk yang terjadi pada proses ini dikarenakan terdapat terdapat 9 motor listrik yang digunakan untuk menggerakkan mesin mesin mill dryer vertical tipe MDV-10. Selain itu, mesin 
mill dryer vertical tipe MDV-10 ini juga menggunakan bahan bakar LPG untuk unit pengeringannya sehingga menyebabkan banyaknya masukan energi hanya untuk proses penepungan. Besarnya penggunaan energi ditentukan oleh tingkat penggunaan sarana produksi dan jumlah produksi yang dihasilkan, semakin tinggi masukan energi dalam proses produksi dan rendahnya hasil produksi yang diperoleh maka akan semakin efektif dan efisien energi yang digunakan.

\section{KESIMPULAN}

1. Uji kinerja mesin menghasilkan efisiensi sebesar 21,15\%, kapasitas aktual dan teoritis sebesar 21,15 $\mathrm{kg} / \mathrm{jam}$ dan $100 \mathrm{~kg} / \mathrm{jam}$, persentase tepung tercecer sebesar $0 \%$, persentase susut massa sebesar 78,82\%, rendemen tepung sebesar 21,18\%, kebutuhan daya total sebesar $6,97 \mathrm{~kW}$, konsumsi bahan bakar lpg sebesar 6,42 kg/jam. Tepung singkong yang dihasilkan sudah memenuhi kategori yang diizinkan dimana memiliki nilai kadar air basis basah sebesar 10,72\% dengan nilai indeks keseragaman 1:7,71:108,46, serta nilai modulus kehalusan dan diameter rata-rata partikel tepung sebesar 0,56 dan 0,006 inci.
2. Penggunaan energi total pada proses pembuatan tepung singkong di Techno Park Pangan Grobogan sebesar 83,881 $\mathrm{MJ} / \mathrm{kg}$ dengan rincian yaitu energi biologis manusia sebesar $0,759 \mathrm{MJ} / \mathrm{kg}$, energi langsung listrik dan bahan bakar sebesar 2,332 MJ/kg, dan energi tidak langsung sebesar $80,79 \mathrm{MJ} / \mathrm{kg}$.

\section{DAFTAR PUSTAKA}

Abdullah, K., A. K. Irwanto, N. Siregar, S. E. Agustina, A. H. Tambunan E. Hartulistiyoso dan Y. A. Purwanto. 1990. Energi dan Listrik Pertanian. Japan International Cooperation Agency. Institut Pertanian Bogor. Bogor

Badan Standarisasi Nasional. 1996. Tepung Singkong: SNI 01-29971996. Jakarta.

Badan Standarisasi Nasional. 2014. Mesin Pengolah Ubi Kayu - Bagian 4: Mesin Penepung Ubi Kayu - Tipe Hammer Mill - Syarat Mutu dan Metode Uji. SNI 0838 - 4 : 2014. Jakarta

Brennan, J. G., J. R. Butlers, N. D. Cowell, dan A. E. V. Lilly. 1990. Food Engineering Operations $3^{\text {th }}$ Edition. Elsevier Publishing Co. London.

Dwiari, S. R., D. A. Danik, Nurhayati, S. Mira, F. Sandi, A. R. Yudhanti, B. K. W. Ida, dan Yoga. 2008. Teknologi Pangan Jilid I. Direktorat Pembinaan Sekolah Menengah Kejurusan Direktorat Jenderal Manajemen Pendidikan Dasar dan Menengah. Departemen Pendidikan Nasional.

Hall, D. O, Rosillo and Calle . 1985. Energy and Resource Quality: The Ecology of Economic Process. John Wiley \& Sons Inc. New York 
Hall, C. W. and D. C. Davis. 1978. Processing Equipment for Agricultural Product 2nd Edition. The AVI Publishing Company, Inc., Westport, Conecticut.

Hasan. 2002. Pokok-pokok Materi Metodologi Penelitian dan Aplikasinya. Ghalian Indonesia. Jakarta

Henderson, S. M. dan R. L. Perry. 1976. Agricultural Process Engineering 3th Editioan. USA: The AVI Publishing Company, Inc.

KLprotech. 2016. Plant Mill Dryer Vertical. PT. Kerta Laksana. Cimahi.

Laksmana, I. 2007. Analisis Efisiensi Penggunaan Energi Pada Industri Gula Tebu di PT. PG. Rajawali II Unit PG. Jatitujuh Majalengka, Jawa Barat. Skripsi. Fakultas Teknologi Pertanian. Institut Pertanian Bogor. Bogor

Leniger, H. A. and W. A. Baverloo. 1975. Food Process Engineering. D. Reidel Publisihing Company, Dordreht, Holland.

Manan, S. 2005. Energi Matahari, Sumber Energi Alternatif yang Efisien, Handal dan Ramah Lingkungan di Indonesia. Program Diploma III Teknik Elektro. Fakultas Teknik, Universitas Diponegoro.

Osamu, K., I. Karaki, C. B. Philip, C. R. Noland, B. M. Jenkins, T. Jungbluth, A. Esper, dan Y. Hashimoto. 1999. CIGR Handbook of Agricultural Engineering Volume $V$. International Commission of Agricultural Engineering, ASAE. Florida

Pimentel, D. 1990. Handbook of Energy for World Agriculture. Elsevier Science Publishing Co., Inc. New York

Purwanto, S. 1995. Perkembangan Produksi dan Kebijakan dalam Peningkatan Produksi Jagung.
Direktorat Budi Daya Serealia, Direktorat Jenderal Tanaman Pangan, Jakarta.

Rangkuti, P. A., H. Rokhani, dan U. S. Kaltika Setya. 2012. Agritech Vol. 32 No. 1, Uji Performansi Mesin Penepung Tipe Disc (Disc Mill) Untuk Penepungan Jumawut (Setaria italica (L.) P. Beauvois). Institut Pertanian Bogor. Bogor.

Regional Network Agriculture and Machinery. 1995. Test Codes and Procedures For Farm Machinery. Unindo, United State of America.

Rijaldi, T. 2006. Buku Ajar Mesin Peralatan. Departemen Teknologi Pertanian. Universitas Sumatera Utara. Medan

Sanders, M. S., and E. J. McCormick. 1987. Human Factors In Engineering and Design, $6^{\text {th }}$ edt. McGraw-Hill Book Company. USA:331-454.

Sholahudin, A. H. 1999. Audit Energi Pada Proses Produksi CPO (Crude Palm Oil) di Pabrik Kelapa Sawit (PKS) Kertajaya PTP Nusantara VIII, Banten Selatan. Skripsi. Fakultas Teknologi Pertanian, Institut Pertanian Bogor. Bogor

Smith, H. P. 1955. Farm Machinery and Equipment Inc. Fourth Edition, Mc Graw-Hill Book Co. New York.

Smith, H. P. 2000. Farm Machinery and Equipment. Mc Graw Hill Publishing Company Ltd, New Delhi.

Stout. 1992. Energy in Farm Production. Elsevier Science Publishing Co., Inc. New York

Suprapti, M. 2005. Teknologi Pengolahan Pangan Tepung Tapioka, Pembuatan \& Pemanfaatannya. Kanisius. Yogyakarta.

Tituk, W. 2010. Seputar Singkong. [Serial Online].http://agrosingkong.wordpr ess.com/singkong-manggu- 
manhihot-esculenta/. [Diakses pada 5 Juli 2017].

Wiratakusumah, A. 1992. Peralatan dan

Unit

Proses

Industri

Pangan.Departemen Pendidikan dan Kebudayaan Direktur Jenderal

PerguruanTinggi. Pusat Antar

Universitas. Institut Pertanian

Bogor. Bogor. 